\title{
Techniques Used for the Preparation and Application of Gold Powder in Ancient China
}

\author{
Zhao Huaizhi and Ning Yuantao \\ Kunming Institute of Precious Metals, Yunnan, 650221, China \\ E-mail:majun@ipm.com.cn
}

Received: 25 March 2000

The preparation and application of gold powder have a long history in China. The ancient Chinese had a deep understanding of the morphology and size of naturally occurring gold powder. In the early stages, the technology for making gold powder probably involved grinding gold on a special stone. Later, the technique of making gold powder from gold foil was developed in the second century $\mathrm{AD}$. The amalgamation technique was also invented in the 2 nd century $\mathrm{AD}$. In ancient China, gold powder was used for a number of applications, including in medicine and for paint and printing silk and paper etc. The techniques used for the application of gold powder in ancient China were the most advanced in the world at that time.

The use of gold has a very long history, going right back to the enlightenment period of civilization. Gold has been used throughout the entire history of civilization and it is easy to turn it into thin leaf (foil) or wire. The origin and development of gold powder occurs later than for gold foil, but there were many references to native gold powder in ancient Chinese books: most of them described the mineralogy of native gold. An example of such a book is 'San-Hai Jing' which also includes descriptions of medical materials, local products, sacrificial rites, etc: of the 18 Chapters, 14 were written in the Zhanguo period ( 475 $-221 \mathrm{BC}$ ); the author is unknown. In 'Nan-San Jing' in, 'San-Hai Jing' it is indicated that "Yongchang (Yunnan, China) produces gold like bran in a stream". The 'Compendium of Materia Medica' (1), a book on Chinese herbal medicine includes a description of the size and shape of natural gold powder. The author of this book was Li Shizhe $(1515-1593 \mathrm{AD})$ who lived in the Ming Dynasty (1368 - 1644 AD). Naturally occurring gold was called "bran gold" and "ash gold". Today gold is classified according to particle size, ie natural gold is described as 'gold lumps', 'coarse gold', 'middle grain gold', 'fine grain gold', or 'gold powder'. Natural gold is visible if it has a particle size above $0.05 \mathrm{~mm}$. The "bran gold" and "ash gold" are 'fine gold' and 'gold powder' respectively. It is clear from this literature that the ancient
Chinese had a deep understanding of the morphology and size of naturally occurring gold powder.

The legend describing the collection by ants of naturally occurring gold powder (2) is of the distant past. This gold powder was known as "pipilika gold" and could have been the remains of fine gold which occurred naturally under the anthill.

There is mention of how gold powder was produced and for what purposes it was used in many writings from ancient China.

\section{MECHANICAL METHODS}

Three mechanical techniques were used in ancient China for making gold powder (3), ie grinding, mixed powder abrasion and mechanical comminution. The 'Compendium of Materia Medica' (1) referred to use of "gold crumb" for medical applications. A book called "Lu Shi" (Ge-Zhi-Gu-Wei) (4) provides historical data from the legend period, and indicates that "jadeite is able to grind gold". It is clear therefore that grinding was a method used in ancient times for making gold powder. 'Gui-Tian-Lu' (5), a book written by $\mathrm{Ou}$ Yanxin (1007 - 1072 AD, Song Dynasty) contains the statement "my home has a jadeite....... The gold powder 
fell in succession when I ground the gold ring on the jadeite". "Xu Bo-Wu Zhi' indicated that "the jadeite can grind gold for making gold powder". There is some confusion as to what is meant by "jadeite" and some thought that it was a 'touchstone' (6).

Abrasion methods were also used for making mixed powder in ancient China : the starting materials were gold foil and Chinese herbal medicines. 'Lun Zhi Zhun-Sheng', a book on treatment criteria mentions a drug called "gold foil pill" made from gold foil, "ni" powder and milk. The mixed raw materials were simmered until the milk became dry, then ground into a mixed powder before making the drug pill. The "ni" powder could be a mixture of calcium carbonate, magnesium silicate and calcium sulfate

Mechanical comminution has been used for the large scale manufacturing of gold powder. 'Wu-Jin Fen-Tu Jue' (7) is a book by $\mathrm{Hu}$ Gangzi which describes the secrets for making metal powders from gold silver, copper, lead, and tin. The author was a famous alchemist and the book was written in the last years of the Donghan Dynasty $(25-220 \mathrm{AD})$, in the middle of the 2 nd century AD. A mechanical method was described for making gold powder, as shown in Figure 1:

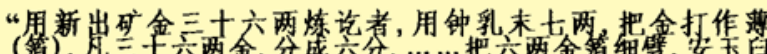

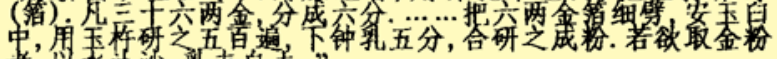 者, 以求汰沙, 乳末自羙。”}

\section{Figure 1}

The text of Figure 1 is as follows:

Take the smelted gold $(578.88 \mathrm{~g})$ and make it into thin leaves by hammering and then it is finely fragmented. The gold is then divided into six portions of $96.48 \mathrm{~g}$. Gold $(96.48 \mathrm{~g})$ is mixed with stalactite powder in a ratio of $1: 5$ and ground in a jade mortar with a jade pestle. This grinding process is repeated 500 times. The powder is then transferred into a vessel containing water, which is thoroughly stirred. The stalactite emulsion is removed mechanically from the surface of the water.

This method was used in China for the preparation of gold powder as early as the 2 nd century $\mathrm{AD}$ and was then used from the 4th century AD in India. It is indeed a large scale manufacturing process for gold powder, using 36 "liang" each time, ie 578.88 g. Based on an ancient weight found by archaeologists near Changsha, Hunan, China (8), and used on a balance in the latter part of the Zhanguo period (475-221 BC), 1 "ling" $=16.08 \mathrm{~g}$.

\section{CHEMICAL METHODS}

In China, in the 2 nd century $\mathrm{AD}$ an alternative large scale manufacturing process for gold powder was proposed by Hu Gangzi (7). He invented a chemical method for making gold or silver powder, in addition to the comminution method mentioned above. This excellent chemical method was described in 'Chu JinKuang Tu-Lu', a well known book. The original text is reproduced in Figure 2:

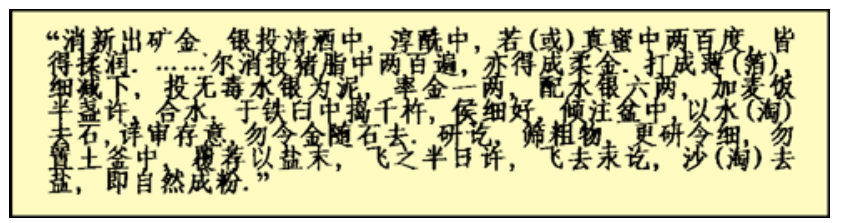

Figure 2

The meaning of the text in Figure 2 is as follows:

First of all the gold surface is cleaned and then the clean gold is cut into fine fragments with scissors. These fine fragments of gold were added to mercury in the ratio of 1 liang ( $16.08 \mathrm{~g}$ ) of gold foil to 6 liang $(96.48 \mathrm{~g})$ of mercury to form an amalgam. Then half a cup of "maifan-shi" is added and mixed with water ("mai-fan-shi" is an aggregate of a variety of minerals). The mixture is placed in a mortar and pounded with a pestle. The process is repeated 1000 times until the pieces of gold foil become fine powder. Then the mixture is transferred to a pan and the sand particles panned out with water. The residue is ground again and the coarse matter screened out before grinding again and adding salt. Then the mixture of amalgam and salt is heated to evaporate the mercury, the salt acting as a dispersing agent. Then the salt is dissolved away to leave the fine gold powder.

The instructions are very clear, and a similar technique was used in India in the 9th century AD (2). The method is very advanced for the time and even today some chemists admire $\mathrm{Hu}$ Gangzi's intelligence and wisdom.

\section{APPLICATIONS FOR GOLD POWDER}

In ancient China, gold powder was used in medicine and in painting and the printing of silk and paper.

One of the earliest uses was in medicine and the use of gold drugs can be traced back as far as $2500 \mathrm{BC}$ ( 9 , $10)$. Since the discovery of gold, mankind has appreciated its durability and naturally associated its longevity with 
eternal life for human beings (11). As a result, people began to seek longevity by eating gold. This practice was described in a book 'On Salt and Iron', written in 81 BC by Huan Kuan of the Western Han Dynasty (202 BC - 8 $A D)$, who said that "immortals swallow gold and pearls in order to enjoy eternal life in heaven and on earth". In the Taoist book entitled 'Zhouyi Cangtonqi' by Wei Boyan of the Eastern Han Dynasty (25 - 220 AD) it is also said that "Gold is the most valuable thing in all the world, because it is immortal and never decays. Alchemists eat it and they enjoy longevity"; but "gold pieces are heavy and cannot stay long in the intestines" ("Compendium of Materia Medica': (1)). Hence people began to swallow gold powder or gold paste. The gold from the powder or paste remained for a long time in the intestines which became golden as a result. Consequently alchemists began to seek soluble gold as an ingredient for "potable gold". For surgical treatment, 'Bencao Zaixin' (10) wrote "grind the gold into powder and apply it to the open wound of the furuncle. When the gold goes deep into the wound it is capable of entirely uprooting the furuncle". In addition, 'Bencao Zaixin' said that gold was capable of removing all the toxins from smallpox and skin ulcers when applied to the affected skin. Until the Ming Dynasty, Li Shizhen (1518 - 1592) made a detailed summary of medicinal applications for gold in his book entitled 'Compendium of Materia Medica' (1).

China is famous for silk production, but ever since $7000 \mathrm{BC}$ cotton clothes have been worn in China. Silk fabrics have been produced in China since about 4000 BC. Techniques for gold metallization of silk were used in the Tang Dynasty $(618-907$ AD). The method used was to print an adhesive onto the silk and then metallize the printed pattern with gold powder. Textile fabric is richer and more colourful than gold brocade; and it is also cheaper to manufacture. During 1975, archaeologists found clothing metallized with gold powder during Huang Shen'grave (1243) in Fu Cang Shan, Fuzhou, China (12). These clothes are representative of printing silk with gold powder in the Southern Song Dynasty (1127-1279 AD).

Gold powder was also applied to calico paper in ancient China. The method used was similar to that used for silks. Gold powder was also used as a colorant in paints and lacquers; gold powder flake was used in this application.

\section{CONCLUSIONS}

By the 2nd century AD two techniques were used in China for the preparation of gold powder, ie mechanical and chemical. According to Hu Gangzhi, the method for making powder from gold foil was handed down from earlier times and was probably used before the amalgamation technique. The amalgamation technique was invented by Hu Gangzi.

The chemical methods introduced were an important improvement for the preparation of fine gold powder. These were based on screening and dispersion with salt.

Gold powder was used in ancient China for treatment of boils and it is claimed that it may have acted as an antibiotic. For the printing of gold on silk or paper, bonding agents and gold flake were used. These application techniques were very advanced for the time.

\section{ABOUT THE AUTHORS}

Professor Zhao Huaizhi is a Research Fellow in the Kunming Precious Metals Institute, China. He has worked with new precious metals materials, especially precious metals-rare earth alloys for many years and has made significant contributions to scientific research. In collaboration with his colleagues he has written some reviews on the history of gold in China.

Professor Ning Yuantao is also a Research Fellow in the Kunming Precious Metals Institute, and works on a variety of research topics related to precious metals materials, especially on catalyst gauzes used for ammonia oxidation in the production of nitric acid.

\section{REFERENCES}

1 S. Li, 'Compendium of Materia Medica', Vol. 2, Part 1, Ming Dynasty (1368 - 1644 AD), Bookshop of China, Beijing, 1988

2 R.K. Dube, Gold Bull., 1991, 24(3), 95

3 H. Zhao and Y. Ning, Guijinshu (Precious Metals), 1999, 20 (2), 50

4 M. Luo, 'Lu Shi (Ge-Zhi-Gu-Wei)' Vol. 2, 37, Song Dynasty (960-1279 AD)

5 Y. Ou, 'Gui-Tian-Lu', Song Dynasty $(960-1279$ AD), Chinese Bookstore, Beijing, 1981

6 J.M. Needham, 'Science and Civilization in China', 1959 (in Chinese), Cambridge University Press, 1976, Vol. 5, Part 2, p.465

7 K. Zhao, 'Studies in the History of the Natural Scionces'(in Chinese), 1984, 3 (3), 224

8 Z. Gao, 'Archeology' (in Chinese), 1972, 4

9 J.M. Needham, 'Science and Civilization in China', Cambridge University Press, 1974, p. 285

10 H. Zhao and Y. Ning, Grijinshu (Precious Metals), 1999, 26 (3), 55

11 G.B. Kauffman, Gold Bull., 1985, 18,69

12 C.Wei, 'Weaving, Embroidery, Dress and Personal Adornment', in 'The Canon of National Treasure', Wenhui Press, 1996, 948 